\title{
Study on the Effect of Jet Velocity on Mixing Performance and Sludge Prevention in Large- -Scale Crude-Oil Tanks by the CFD Technique
}

DOI: $10.15255 / K U I .2016 .012$ $\mathrm{KUI}-17 / 2017$

Original scientific paper Received April 1, 2016 Accepted June 29, 2016

\author{
A. A. Lotfi Neyestanak, ${ }^{a^{*}}$ M. R. Tarybakhsh, ${ }^{\mathrm{b}}$ and S. Daneshmand \\ a Department of Engineering, Yadegar -e- Imam Khomeini (RAH) Shahre Rey Branch, \\ Islamic Azad University, Tehran, Iran \\ ${ }^{b}$ Department of Chemical Engineering, Iran University of Science \& Technology, Tehran, Iran \\ 'Department of Mechanical Engineering, Majlesi Branch, Islamic Azad University, Isfahan, Iran
}

\begin{abstract}
$\|$ Abstract
In this paper, computational fluid dynamic modelling was developed to study the effect of the floating jet velocity or submerged rotary jet in sludge prevention in a large crude-oil storage tank. The Euler-Euler method was used in a two-dimensional CFD model to describe oil and sludge flow behaviour at the bottom of the storage tank. By modifying some parameters, the k-e model was used to describe the turbulence of the mixing flow. The results show the effect of jet velocity, angle, and time on the mixing process. By increasing the velocity from $5 \mathrm{~m} \mathrm{~s}^{-1}$, the mixing pattern significantly changes and improves the mixing of the sludge with crude oil. To evaluate the results, chosen was the sludge profile related to the bottom of the sample tank, and modelling results showed an $80 \mathrm{~cm}$ reduction in thickness of the sludge, which corresponds well to the profile of the bottom of the tank. In addition, the $y^{+}$axis indicated that the amounts at all points were less than 300 , which is acceptable in two-phase modelling.
\end{abstract}

\section{\| Keywords}

Submerged rotary jet mixer, large-scale oil storage tank, sludge prevention, modelling of fluid flow, computational fluid dynamics, Euler-Euler method

\section{Introduction}

The jet mixer is one of the simplest pieces of equipment used in different processes as a good substitute for the conventional technique (using impeller) for 50 years. The reduction in contact surface, efficiency, and mixing time is achieved by using the disturbance factor effectively. ${ }^{1}$ In comparison with mechanical agitators/mixers, jet mixers cause more turbulence, higher shear rate, vortex motion, and high-speed mixing in a short time without the impetus element. The high level of turbulence leads to less dead points in shallow parts or square storage tanks. Jet mixers are more effective if there is a shear stress besides mixing. The $S R J^{* *}$ is thus a good example of this case, which is why it was simulated and investigated in the present study. The jet mixing process has different active research fields in a wide range of processes, such as chemical extraction, chemical reaction, absorption, desorption, reaction injection moulding (RIM) mixture, etc. ${ }^{2}$ In jet mixing, a part of the fluid existing in the tank moves at high velocity into the tank with the use of a pump and through nozzles. Jet mixers have more advantageous compared to mixers with impellers. They are installed more easily, and jet mixing leaves less dead zones in rectangular and shallow tanks than do mixers. The jet mixer is more efficient if cutting is needed besides mixing. In gas/fluid systems, jet mixers use $20-40 \%$ less energy (Fig. 1 (A)). In the mixing process by SRJ and by use of a high-pressure fluid jet, part of the heavy oil starts to circulate at high velocity (Fig. 1 (B)). ${ }^{3}$

${ }^{*}$ Corresponding author: Ali Akbar Lotfi Neyestanak email: aklotfi@gmail.com

${ }^{* *}$ Submerged rotary jet
Thus, the fluid jet in the tank forms a circular pattern, which causes movement of sludge and heavy oil from the bottom of the tank towards the middle and the top of the tank, ending up in a mixture of these two fluids. ${ }^{4}$ In this paper, a CFD Euler-Eulerian multiphase model has been used to study the mixing process of crude oil-sludge in a large storage tank with maintenance preventive approach. The CFD model, as a robust tool, can model this complex multiphase system. As a case study, the mixing process in the tanks located in Khark Island, was studied by this modelling technique in order to design a proper system for achieving optimized mixing, in addition to studying the effect of jet parameters on the mixing process.

Much research has been conducted on jet mixers and many mathematical relations have been offered to measure the mixing time. A relation based on the tank diameter and jet velocity and diameter was given by Fossett and Poos$\mathrm{er},{ }^{5}$ but their research showed no relationship between the Reynold's number and mixing time. On the other hand, Fox and $\mathrm{Gex}^{6}$ showed that mixing time was dependent on the Reynold's number of the jet, and this relationship is stronger in laminar flow than turbulent flow. Coldrey ${ }^{7}$ reported that a stronger jet results in more effective mixing in the side entry jet system, which causes reduction in mixing time. Lane and Rice ${ }^{8}$ used an inclined jet in their investigations. Maruyama ${ }^{9}$ found that in the circulation flow mixing and Reynold's number above 30 000, there was an optimized nozzle depth for faster mixing. If liquid depth equals the tank diameter, this amount will range from the liquid surface to $3 / 4$ of liquid depth, but if it is less than the tank diameter, the amount will be in the middle depth. By use of modelling, Ranade ${ }^{10}$ described the mixing and flow pat- 

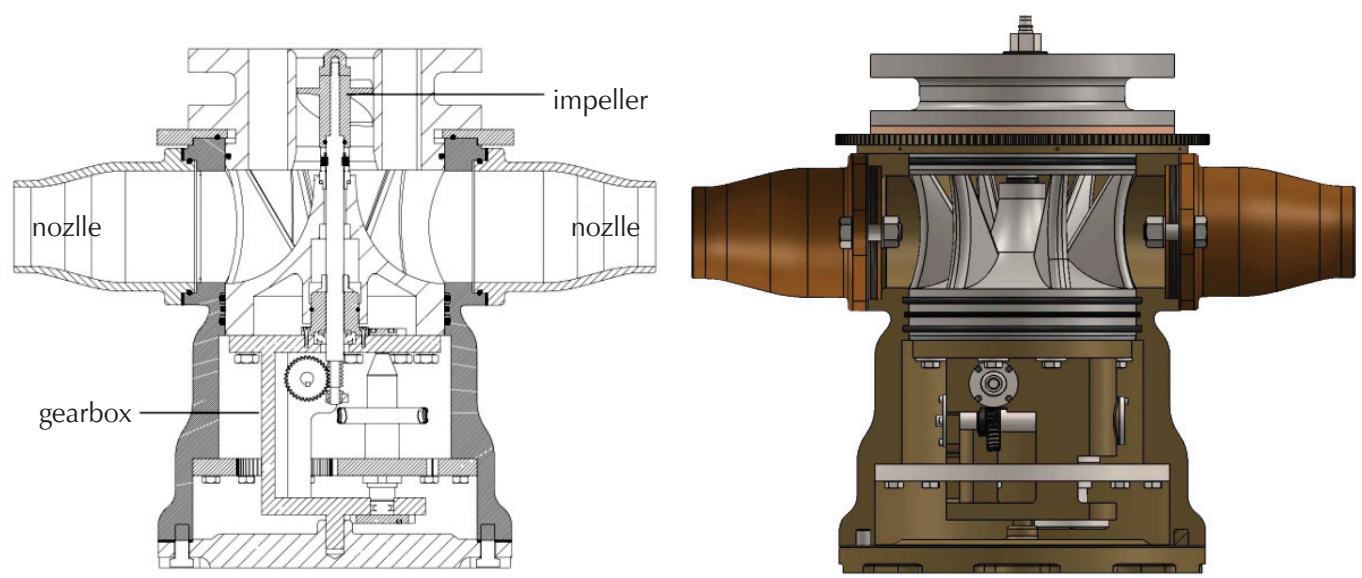

(A)

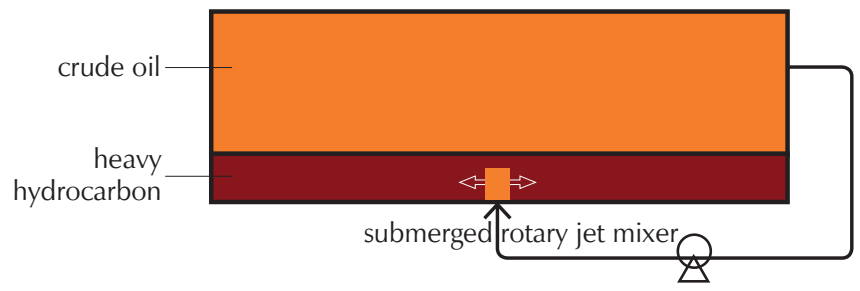

(B)

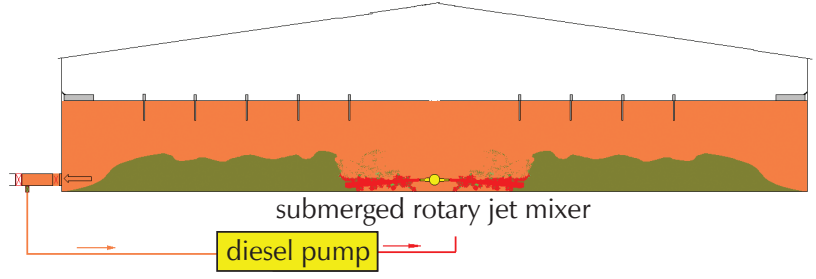

(C)

Fig. 1 - (A) Schematic view of submerged rotary jet mixer machine (SRJ); (B) Mixing process in an oil storage tank; (C) Schematic view of an SRJ in a storage tank with sludge problem

tern in a tank equipped with a jet mixer. Jayanti1 ${ }^{11}$ studied the recycling flow pattern in jet mixers by applying computational fluid dynamics (CFD) and coding, and found that flat, elliptical, half-circle and cone bottom tanks are more practical for the mixing process. Studies have shown that the circulation flow pattern is considerably dependent on the tank shape, whereas mixing time is significantly dependent on the circulation flow pattern. A. W. Patwardhan ${ }^{12}$ compared experimental data with modelling results, and found that mixing time is a function of nozzle diameter and jet inclination angle, moreover, showed that the nozzle diameter had an inverse relation to the jet inclination angle, and direct relation to power. Zughbi $i^{13}$ performed research on the effect of jet height and angle by applying CFD technique in addition to the effect of jet angle on mixing time. For a side-entry jet, and with two conditions; ratio of height to diameter of 1 and maximum length of the jet corresponding to the injection angle of $45^{\circ}$, the minimum mixing time was not achieved, but was obtained at the angle of $30^{\circ}$. The end of the mixing process is defined based on the existing steady state of a component composition at a specific point.

\section{Experimental}

\subsection{Numerical modelling}

The first step in multiphase problems leads to choosing the equations, and proper solution is determining the flow pattern. The two main approaches are Euler and Lagrange methods, but because the volume fraction in these two approaches is not negligible, the Euler-Euler model and Euler method have been used in the present study. The Eulerian model theory is the most complicated model for multiphase systems. In this model, the types of continuity and momentum equations have been solved for each phase. Equation coupling is based on interface conversion factor and pressure. As a result of coupling, the model behaviour is a function of existing phases. Liquid-solid flow is different from liquid-liquid. Moreover, interphase momentum exchange is depended on the mixed type. Volume of fluid, which is indicated by $\alpha_{q}$, is used to specify two-phase conditions in the tank as a continuously penetrating environment. Volume fraction shows the space occupied by each phase. In addition, integration besides mass and momentum conservation laws are separately considered for each phase. The volume of each phase $V_{q}$ is defined by Eq. (1).

$$
V_{q}=\int_{V} \alpha_{q} d V
$$

where:

$$
\sum_{q=1} \alpha_{q}=1
$$

and the effective density of phase $q$ is:

$$
\hat{\rho}_{q}=\alpha_{q} \rho_{q \prime}
$$

where $\rho_{q}$ is the density of each phase. 


\section{Conservation equation}

Before modelling, it is necessary to integrate the equations that show momentum and mass variation in each phase.

\section{Continuity equation}

The continuity equation for phase $q$ is:

$$
\frac{\partial}{\partial t}\left(\alpha_{q} \rho_{q}\right)+\nabla\left(\alpha_{q} \rho_{q} \vec{v}_{q}\right)=\sum\left(\dot{m}_{p q}-\dot{m}_{q p}\right)+S_{q}
$$

In Eq. (4), $\vec{v}$ is phase velocity, $\dot{m}_{p q}$ is mass transport from phase $p$ to $q$, and $\dot{m}_{q p}$ is mass transport from phase $q$ to $p$. $S_{q}$ is a constant mass source that is considered zero in this modelling.

\section{Liquid-liquid momentum equation}

The continuity equation for phase $q$ is:

$$
\begin{aligned}
& \frac{\partial}{\partial t}\left(\alpha_{q} \rho_{q} \vec{v}_{q}\right)+\nabla\left(\alpha_{q} \rho_{q} \vec{v}_{q} \vec{v}_{q}\right)= \\
& =-\alpha_{q} \nabla p+\nabla \overline{\bar{\tau}}_{q}+\alpha_{q} \rho_{q} \vec{g}+ \\
& \quad+\sum_{p=1}^{n}\left(\vec{R}_{p q}+\dot{m}_{p q} \vec{v}_{p q}-\dot{m}_{q p} \vec{v}_{q p}\right)+ \\
& \quad+\left(\vec{F}_{q}+\vec{F}_{\text {lift, }, q}+\vec{F}_{\mathrm{vm}, q}\right)
\end{aligned}
$$

Stress-strain tensor, $\overline{\bar{\tau}}_{q}$ is:

$$
\overline{\bar{\tau}}_{q}=\alpha_{q} \mu_{q}\left(\nabla \vec{v}_{q}+\nabla \vec{v}_{q}^{\top}\right)+\alpha_{q}\left(\lambda_{q}-\frac{2}{3} \mu_{q}\right) \nabla \overrightarrow{v_{q}} \overline{\bar{l}}
$$

$\mu_{q}$ and $\lambda_{q}$ are respectively shear viscosity and bulk of phase $q . F_{q}$ is external force and $\vec{F}_{\text {lift, } q}$ is a lift force.

\section{Mixture model $k-\varepsilon$}

$$
\begin{aligned}
\frac{\partial}{\partial t}\left(\rho_{m} k\right)+ & \nabla\left(\rho_{m} \vec{v}_{m} k\right)=\nabla\left(\frac{\mu_{t, m}}{\sigma_{k}} \nabla k\right)+C_{k, m}+\rho_{m} \varepsilon \\
\frac{\partial}{\partial t}\left(\rho_{m} \varepsilon\right) & +\nabla\left(\rho_{m} \vec{v}_{m} \varepsilon\right)= \\
& =\nabla\left(\frac{\mu_{t, m}}{\sigma_{k}} \nabla \varepsilon\right)+\frac{\varepsilon}{k}\left(C_{1 \varepsilon} G_{k, m}-C_{2 \varepsilon} \rho_{m} \varepsilon\right)
\end{aligned}
$$

The studied system is an oil storage tank with dimensions of $114 \mathrm{~m} \times 7 \mathrm{~m}$ which is floated as a ceiling and contains one meter of sludge (from tank bottom) and the rest is crude oil. The nozzle, placed at a distance of $80 \mathrm{~cm}$ from tank bottom, has a diameter of $100 \mathrm{~mm}$, and receives crude oil from upper layer and jets it into the sludge with a velocity of $46 \mathrm{~m} \mathrm{~s}^{-1}$ (Fig. 2). Gambit software is required to design and mesh the system for modelling. The mesh of crude oil part is a regular triangle type, and the mesh of nozzle and sludge part is an irregular triangle type. This mesh model is shown in Fig. 3. Boundary condition in the jet entrance is the crude oil velocity of $46 \mathrm{~m} \mathrm{~s}^{-1}$ and output is also put on the right wall in the crude oil part. This provided the model is unstable and has been solved by considering $0.008 \mathrm{~S}$. In practical conditions, gravity is considered $g=9.81$. In addition, because of the acceleration of fluid jet as compared to steady sludge flow, it is necessary to regard the virtual mass force in modelling. Input fluid specifications are determined on the basis of one million-barrel tank located on Khark Island. Input fluid is crude oil with viscosity of $0.00975 \mathrm{~kg} \mathrm{~m}^{-1} \mathrm{~s}^{-1}$ and density of $858 \mathrm{~kg} \mathrm{~m}^{-3}$, whereas output fluid is a fluid with viscosity of $0.05 \mathrm{~kg} \mathrm{~m}^{-1} \mathrm{~s}^{-1}$ and density of $930 \mathrm{~kg} \mathrm{~m}^{-3}$ like heavy oil (Table 1). In the crude oil part, fraction of crude oil is considered $100 \%$ and in the sludge $5 \%$.

Table 1 - CFD model input data

\begin{tabular}{l|c}
\hline Input parameters & Value \\
\hline inlet crude oil viscosity & $9.75 \cdot 10^{-3} \mathrm{~kg} \mathrm{~m}^{-1} \mathrm{~s}^{-1}$ \\
crude oil density & $8.58 \cdot 10^{2} \mathrm{~kg} \mathrm{~m}^{-3}$ \\
heavy crude oil viscosity & $5.0 \cdot 10^{-2} \mathrm{~kg} \mathrm{~m}^{-1} \mathrm{~s}^{-1}$ \\
heavy crude oil density & $9.30 \cdot 10^{2} \mathrm{~kg} \mathrm{~m}^{-3}$ \\
inlet jet velocity & $4.6 \cdot 10^{1} \mathrm{~m} \mathrm{~s}^{-1}$ \\
\hline
\end{tabular}

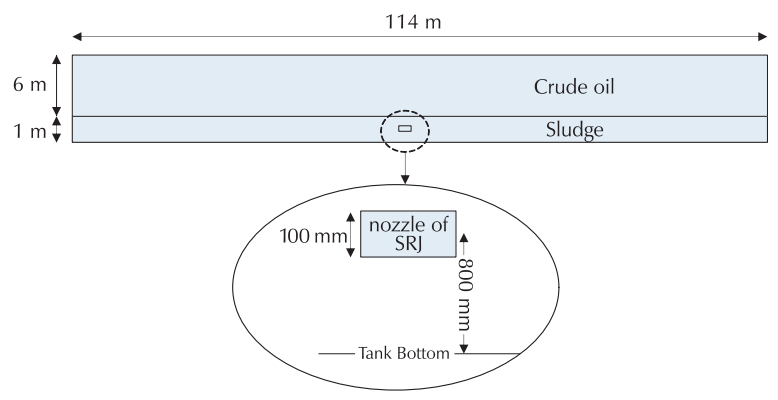

Fig. 2 - Dimensions of the studied SRJ system

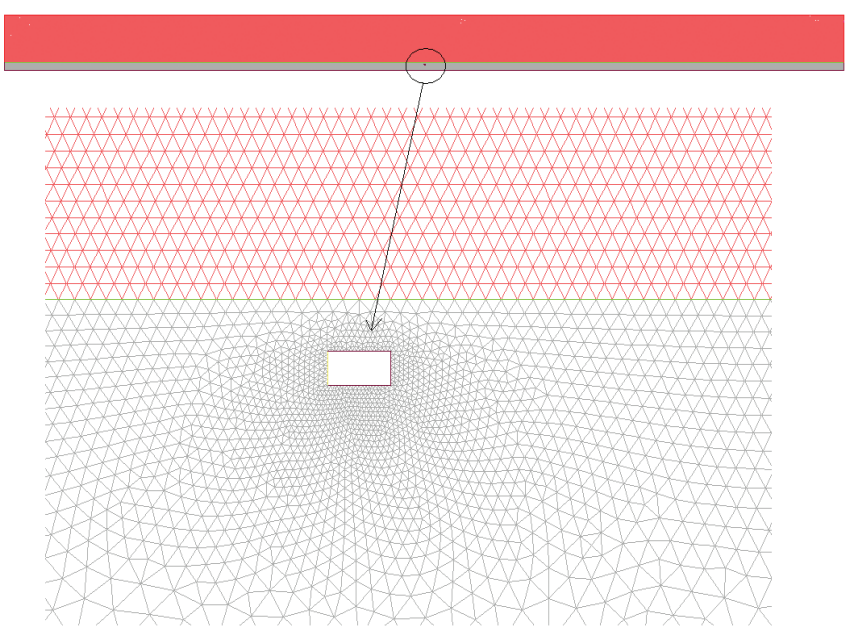

Fig. 3 - Mesh model of the SRJ system 


\section{Results and discussion}

A simple pressure-velocity algorithm, standard pressure, and first-order upwind discretization momentum were applied to solve and k-e model was used to predict the turbulent behaviour of the fluid. Proper setting in solution control was done in order to obtain better convergence during the solving, and the results were recorded at different times. The behaviour of turbulent jet depends on different factors, such as jet parameters, crude oil properties, geometrical parameters of the tank, etc. In this survey, the effective factors of floating jet flow on removal of the sludge were studied. Therefore, all jet and crude oil parameters, and the effective geometrical parameters on the flow of circular floated jets were studied using dimensional analysis of relevant dimensionless equations. The CFD model was used to study the quality of these relations. The effect of jet parameters is considered as a main effective factor in the mixing process and distribution of jet flow in acceptor fluid besides geometrical and environmental parameters.

\subsection{Primary multiphase modelling}

Modelling was performed with CFD, and the primary results showed proper mixing in the first minutes of SRJ system operation. Fig. 4 indicates the changes in sludge ratio inside the tank at different times. According to this figure, there is no proper mixing in the first 46 seconds of system operation because of the circulating flow and high velocity of the jet. Fig. 5 illustrates the results of velocity variations in the storage tank. Mixing begins with forming patterns of circulating systems, and then the increase in number and power of these patterns during time causes a sharp rise in mixing.
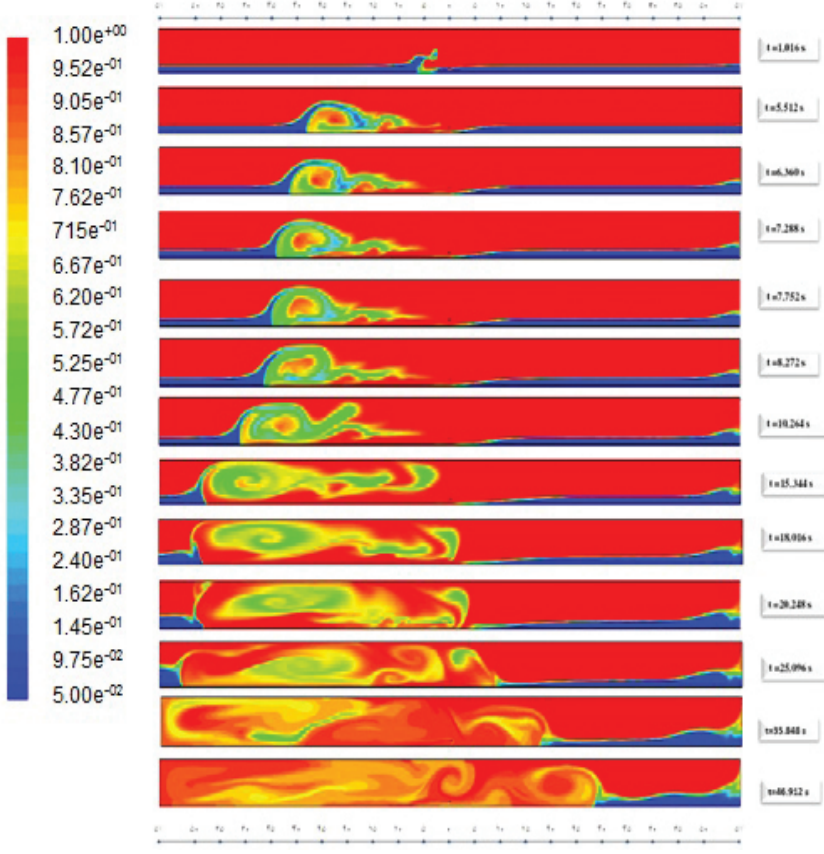

Fig. 4 - Sludge ratio over time

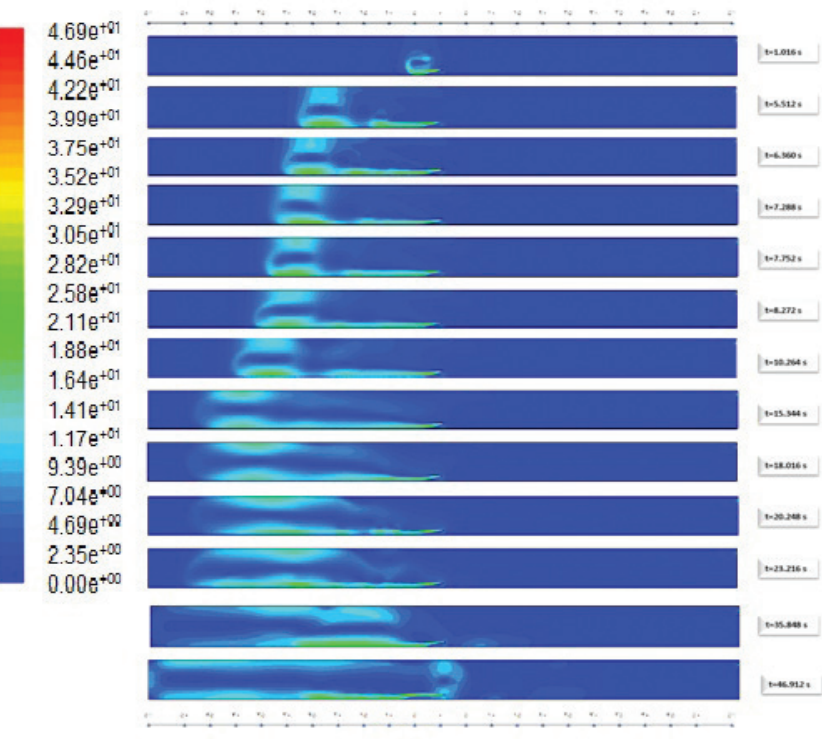

Fig. 5 - Changes in jet velocity model of oil over time

\subsection{Study of jet velocity effects on the mixing process}

Jet velocity is the main factor in improving mixing quality. In this regard, four models with velocities of $5 \mathrm{~m} \mathrm{~s}^{-1}, 10 \mathrm{~m} \mathrm{~s}^{-1}$, $15 \mathrm{~m} \mathrm{~s}^{-1}$, and $30 \mathrm{~m} \mathrm{~s}^{-1}$ were provided. CFD modelling was then performed, and finally the results were investigated at two times of $1 \mathrm{~s}$ and $5 \mathrm{~s}$. Mixing and velocity of different models of each time are reported, and the effect of velocity variations was studied.

\section{Jet emission and velocity model within $1 \mathrm{~s}$}

In this section, the effects of variation in jet velocity of crude oil are investigated inside the sludge in the primary time. Modelling was performed in four different conditions with variable velocities of 5, 10, 15, 30, and $46 \mathrm{~m} \mathrm{~s}^{-1}$. In Fig. $6-\mathrm{C}$, the jet model and its velocity gradient are illustrated at the velocity of $15 \mathrm{~cm}$ within the first second. The rise in velocity causes rapid penetration, but these changes are not very sensible compared with the previous condition, and shows that entering into the boundary leads, in the beginning, to the mixing of the floated jet inside the sludge at the bottom of the tank. In other words, for a storage tank with a diameter of $114 \mathrm{~m}$, effective mixing occurs at the velocity of $15 \mathrm{~m} \mathrm{~s}^{-1}$.

In addition, an increase in velocity through the following steps is just to cover the whole tank. As seen in Fig. 6D, there were no significant changes in velocity gradient when the velocity had increased up to $30 \mathrm{~m} \mathrm{~s}^{-1}$, and the effect of this variation can only be investigated by increasing time in addition to studying the mixing process.

\section{Mixing model and volume fraction within $1 \mathrm{~s}$}

As the mixing process begins at the velocity of $5 \mathrm{~m} \mathrm{~s}^{-1}$, low penetration is observed in sludge with regard to the rapid spread of the velocity distribution model. This caused a 

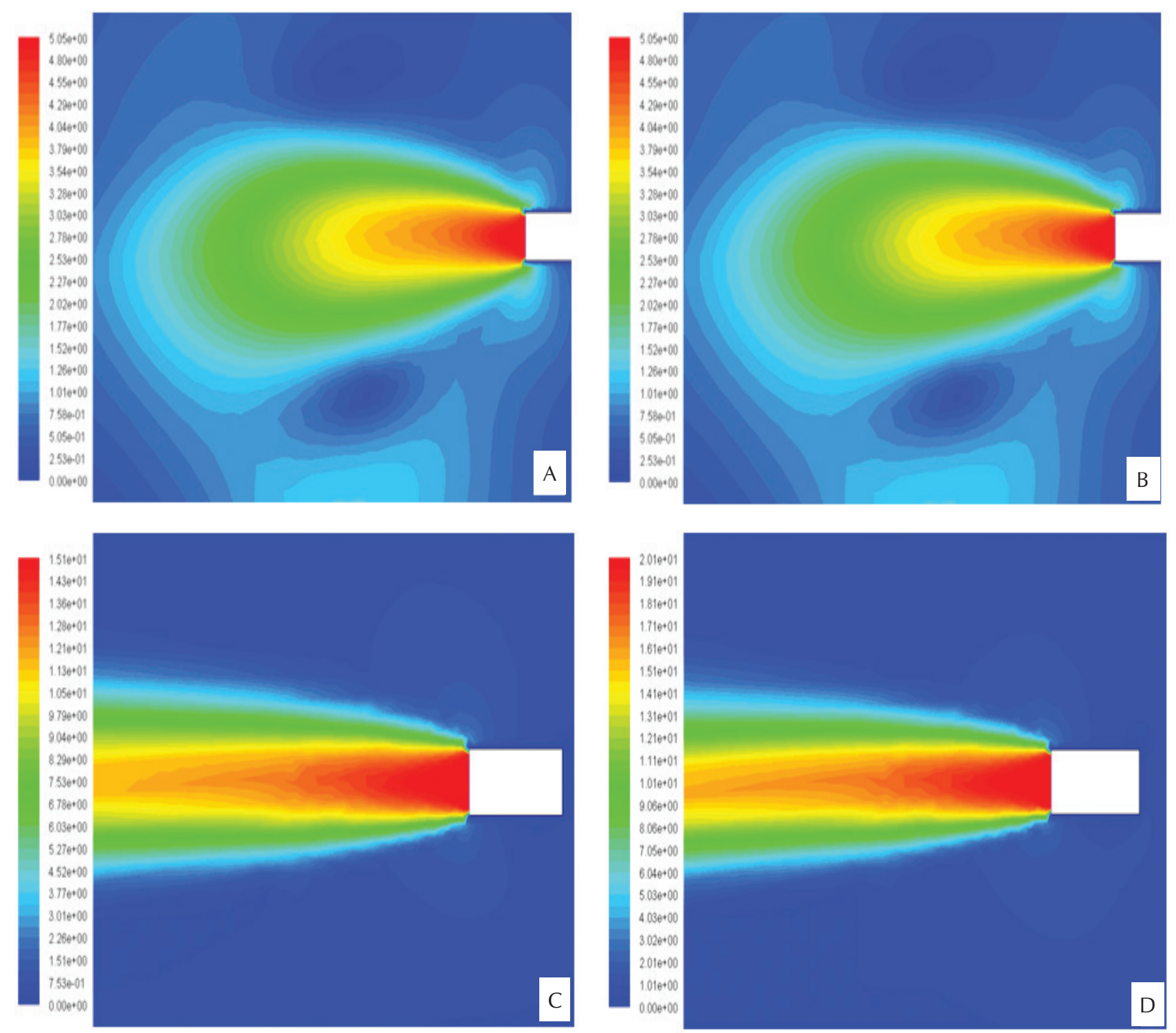

Fig. 6 - Jet velocity distribution model at the distance of $800 \mathrm{~mm}$ from the tank bottom within $1 \mathrm{~s}$ and at the velocity of (A) $5 \mathrm{~m} \mathrm{~s}{ }^{-1}$, (B) $10 \mathrm{~m} \mathrm{~s}^{-1}$, (C) $15 \mathrm{~m} \mathrm{~s}^{-1}$, (D) $30 \mathrm{~m} \mathrm{~s}^{-1}$

sharp increase in mixing time and reduction in jet range, which is obvious from the results (Fig. 7A).

The effect of a jet with velocity of $5 \mathrm{~m} \mathrm{~s}^{-1}$ at the beginning of the mixing process after one second showed low penetration of the jet into the sludge. By increasing in the velocity to $10 \mathrm{~m} \mathrm{~s}^{-1}$ and subsequently significant changes in penetration and velocity model (Fig. 7B), jet mixing and penetration improved compared to previous conditions. The jet fluid could not penetrate the lower layers of sludge and remained at the surface. This problem can be solved by increasing velocity. According to previous modelling, the penetration of the jet into the lower layers at a velocity of $15 \mathrm{~m} \mathrm{~s}^{-1}$ is predictable but does not happen. This could be explained by the steady state of spread diameter and velocity model of the centre (Fig. 7C). When the velocity was increased to $30 \mathrm{~m} \mathrm{~s}^{-1}$, the jet emission radius and penetration diameter improved noticeably (Fig. 7D). The jet then expanded its penetration down to the lower layers and the sludge concentration at the bottom of the tank had reduced from $95 \%$ to $75 \%$ at some points (Fig. 7D), indicating that the velocity was acceptable for mixing. When the velocity was increased to $46 \mathrm{~m} \mathrm{~s}^{-1}$, the penetration depth and mixing rate improved gradually, and at some points at the tank bottom, the sludge concentration sharply reduced from $95 \%$ to $57 \%$ in only one second (Fig. 8). This indicated that an increase in velocity had a greater effect on improving the mixing process. 


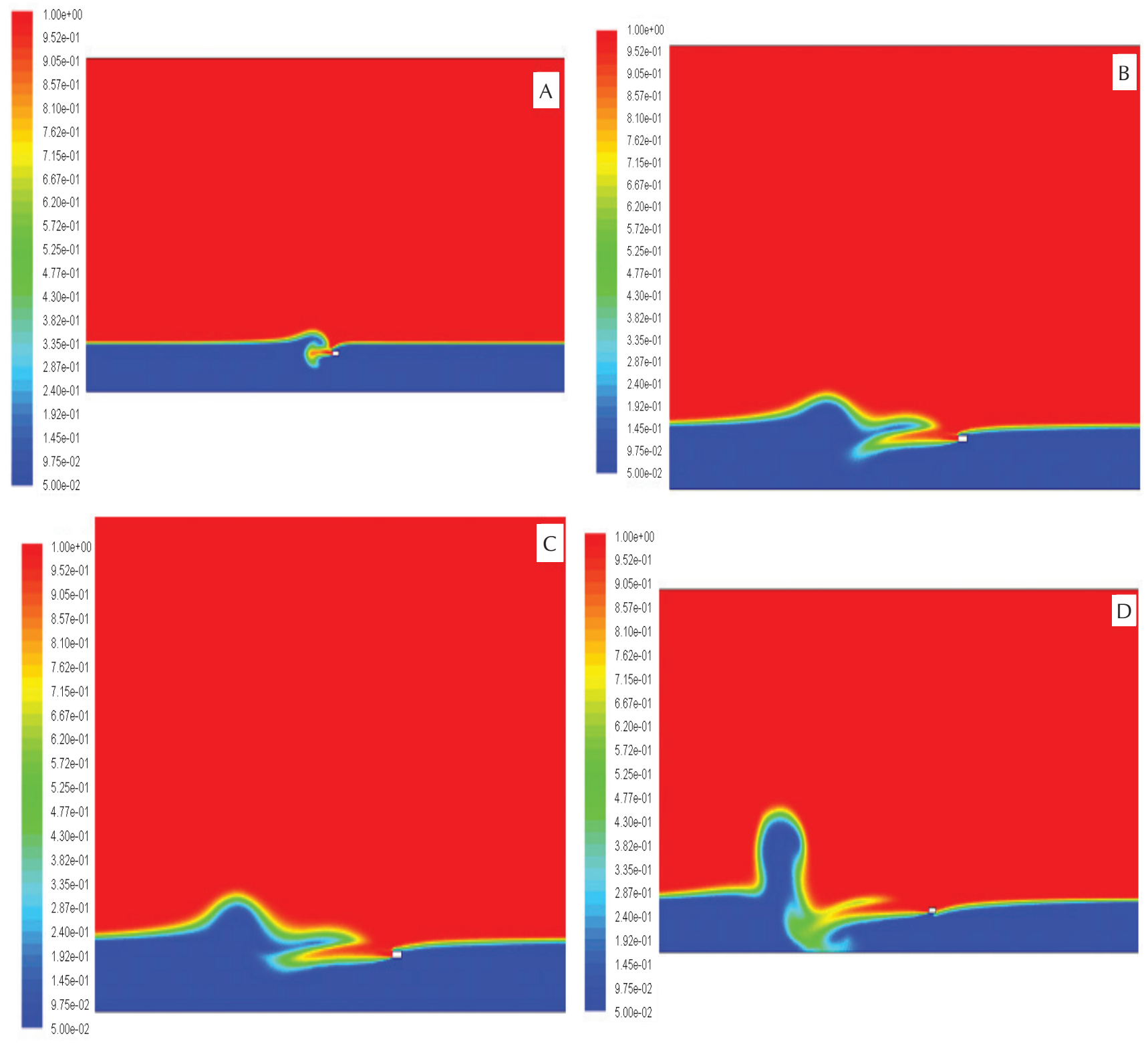

Fig. 7 - Jet mixing gradient at the distance of $800 \mathrm{~mm}$ from the tank bottom within $1 \mathrm{~s}$ and at the velocity of (A) $5 \mathrm{~m} \mathrm{~s}^{-1}$, (B) $10 \mathrm{~m} \mathrm{~s}^{-1}$, (C) $15 \mathrm{~m} \mathrm{~s}^{-1}$, (D) $30 \mathrm{~m} \mathrm{~s}^{-1}$

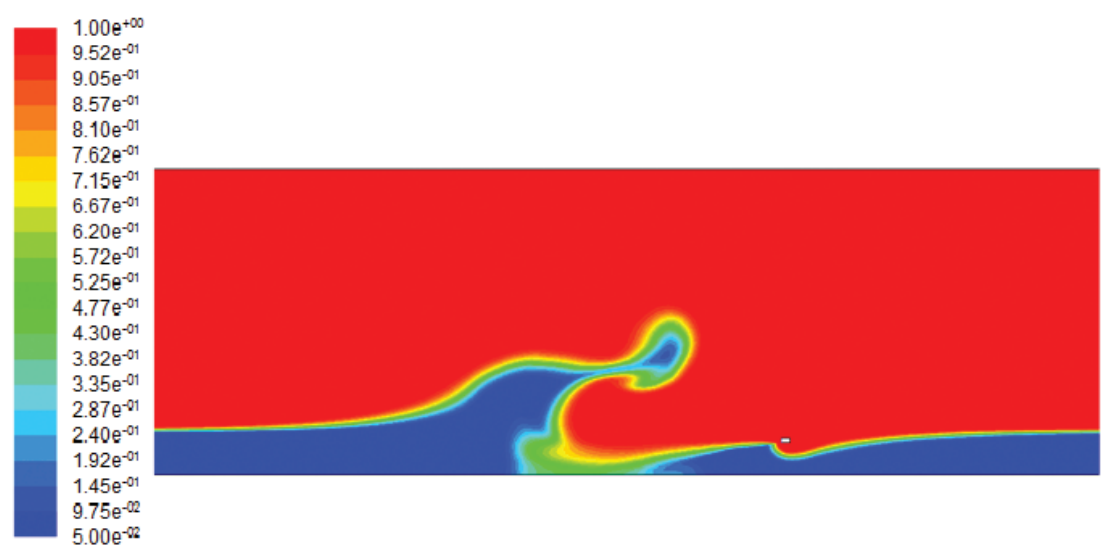

Fig. 8 - Jet mixing gradient of the velocity of $46 \mathrm{~m} \mathrm{~s}^{-1}$ and at the distance of $800 \mathrm{~mm}$ from the tank bottom within $1 \mathrm{~s}$ 


\section{Velocity model and jet emission within $5 \mathrm{~s}$}

In this part, the effect of changes in velocity of the crude oil jet in the sludge within $5 \mathrm{~s}$ is studied. Modelling was done for four velocities: $5 \mathrm{~m} \mathrm{~s}^{-1}, 10 \mathrm{~m} \mathrm{~s}^{-1}, 15 \mathrm{~m} \mathrm{~s}^{-1}, 30 \mathrm{~m} \mathrm{~s}^{-1}$, and $46 \mathrm{~m} \mathrm{~s}^{-1}$. The velocity gradient and jet pattern at the velocity of $5 \mathrm{~cm}$ in five seconds is indicated in Fig. 9A. Considering the velocity model related to the first second, it is obvious that the penetration length of the jet had increased and its width had reduced over time. This condition results in a higher mixing rate and better de-sludge process. The mixing model in the fifth second with velocities of $5 \mathrm{~m} \mathrm{~s}^{-1}$ and $10 \mathrm{~m} \mathrm{~s}^{-1}$ is given in Figs. 9B, C. Studying the velocity gradient showed that there was no significant variation in the velocity model with the passing of time, but only caused a rise in the jet path.

\section{Mixing model and volume fraction within $5 \mathrm{~s}$}

The mixing process at a velocity of $5 \mathrm{~m} \mathrm{~s}^{-1}$ performed better at the lower layers considering the increase in penetration length and velocity distribution model. This phenomenon occurred in the first second, thus leading to better mixing time (Fig. 10).
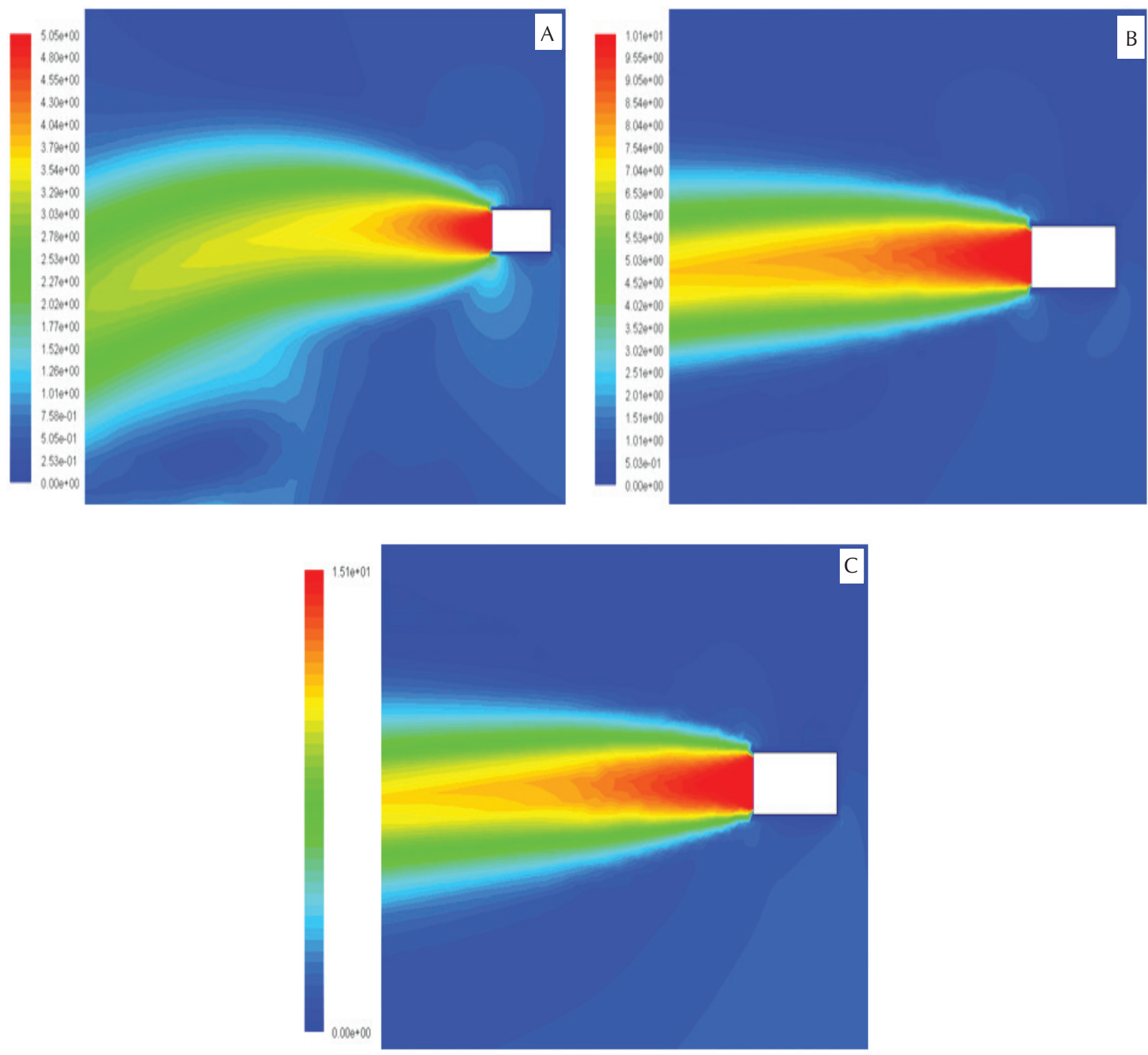

Fig. 9 - Jet velocity distribution model of the velocity of $5 \mathrm{~m} \mathrm{~s}^{-1}$ and at the distance of $800 \mathrm{~mm}$ from the tank bottom within $5 \mathrm{~s}$ 
According to Figs. $10 \mathrm{~A}$ and $\mathrm{B}$, in a jet with velocity of $10 \mathrm{~m} \mathrm{~s}^{-1}$, by increasing vertical penetration velocity over time into the lower layers, a more horizontal penetration was also observed. This vertical penetration resulted in starting the circulatory flow inside the storage tank, increasing mixing, and subsequently reducing mixing time. The volume fraction of sludge had reduced up to $65 \%$ at some points. The jet mixing gradient of the velocity of $30 \mathrm{~m} \mathrm{~s}^{-1}$, at the distance of $800 \mathrm{~mm}$ from the tank bottom within $5 \mathrm{~s}$ is illustrated in Fig. $10 \mathrm{C}$. It is noticeable that, although the mixing pattern is too similar in the first second for two velocities of $10 \mathrm{~m} \mathrm{~s}^{-1}$ and $15 \mathrm{~m} \mathrm{~s}^{-1}$, the mixing pattern in the fifth second and velocity of $5 \mathrm{~m} \mathrm{~s}^{-1}$ improved significantly compared to the velocity of $10 \mathrm{~m} \mathrm{~s}^{-1}$. The main reason for this is the production of circulatory patterns in the tank, as well as the higher shearing stress of the jet with the velocity of $30 \mathrm{~m} \mathrm{~s}^{-1}$ observed clearly with the passing of time. Final- ly, according to Fig. 10D, the desirable condition, i.e. complete de-sludge from the bottom of the tank, was achieved with the velocity of $46 \mathrm{~m} \mathrm{~s}^{-1}$ that causes more powerful circulatory flow (due to high velocity).

\subsection{Evaluation and verification of the results of the two-dimensional model}

There are two main methods to evaluate the model; in the first, the model itself was used to assess and investigate the results, but the second model was based on the experimental results. According to the first approach, mass balance error of the model was $5 \cdot 10^{-6}$, indicating exact solution in model and boundary conditions. $y^{+}$data were assessed to confirm the results. Less acceptable quantities

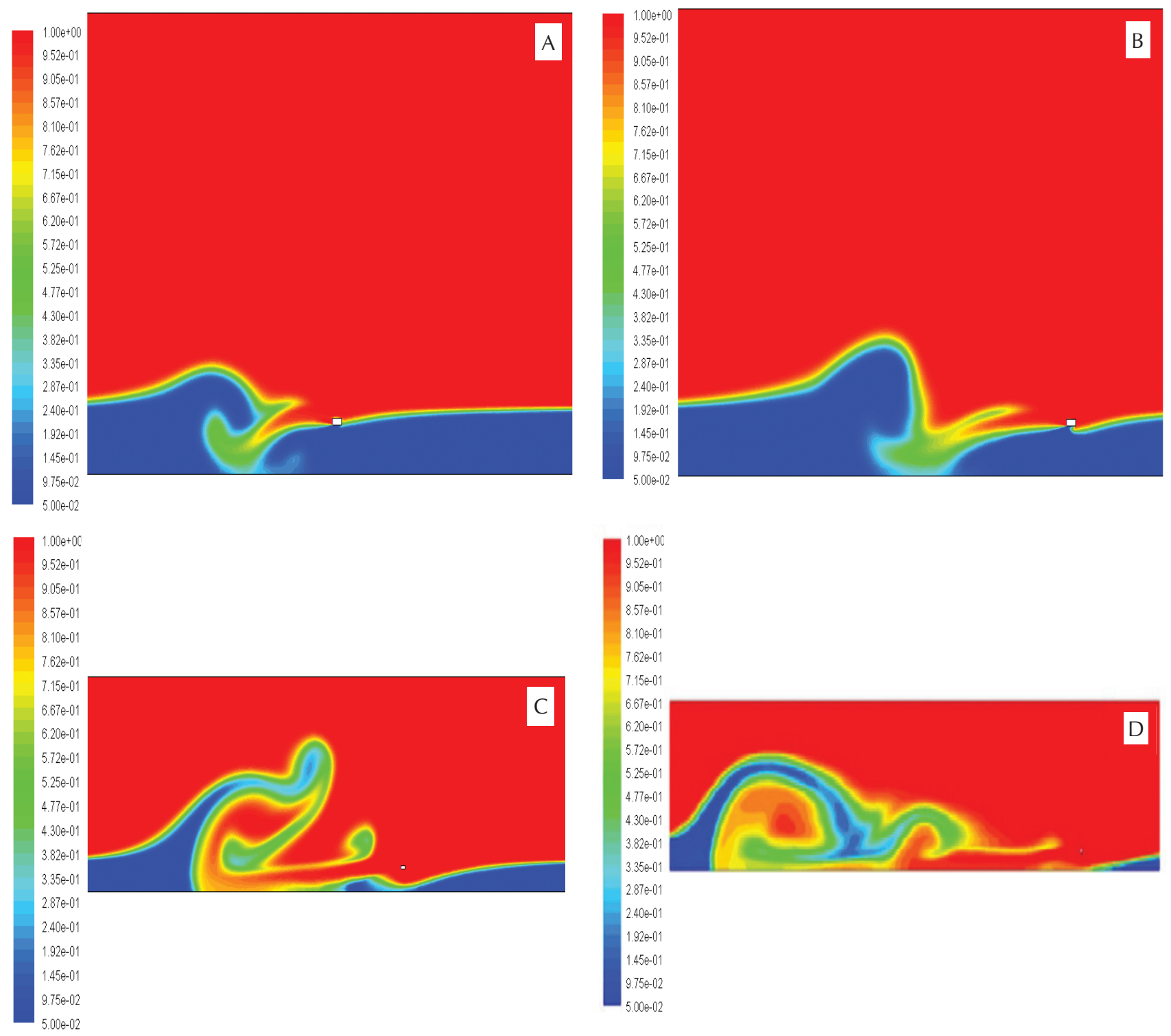

Fig. 10 - Jet mixing gradient of the velocity of (A) $5 \mathrm{~m} \mathrm{~s}^{-1}$, (B) $10 \mathrm{~m} \mathrm{~s}^{-1}$, (C) $30 \mathrm{~m} \mathrm{~s}^{-1}$, (D) $46 \mathrm{~m} \mathrm{~s}^{-1}$ at the distance of $800 \mathrm{~mm}$ from the tank bottom within $5 \mathrm{~s}$ 
of $y^{+}(<300)$ include the sludge at the wall and bottom of the tank (Fig. 11).

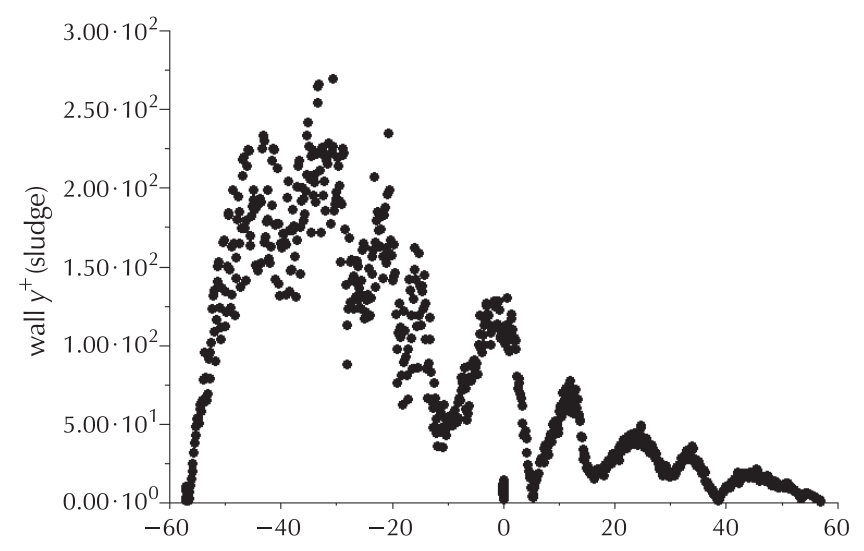

Fig. $11-y^{+}$diagram of down wall

\subsection{Residual diagram}

For solution convergence, study of residual diagram is needed, which includes the following parameters:

1. Continuity: mass continuity

2. U-crude-oil: crude oil velocity in $x$ direction

3. V-crude-oil: crude oil velocity in $y$ direction

4. U-crude-oil: sludge velocity in $x$ direction

5. V-crude-oil: sludge velocity in $y$ direction

6. K-crude-oil: kinetic energy of turbulent

7. Eps-crude-oil: disappearance rate of turbulent

8. VF of sludge: volume fraction of sludge

According to Fig. 12, the residual amounts converged up to $1 \cdot 10^{-2}$, which is an acceptable quantity. On the other hand, turbulent parameters converged to less than $1 \cdot 10^{-3}$, and velocity parameters up to $1 \cdot 10^{-7}$, convergence conditions were completely observed.

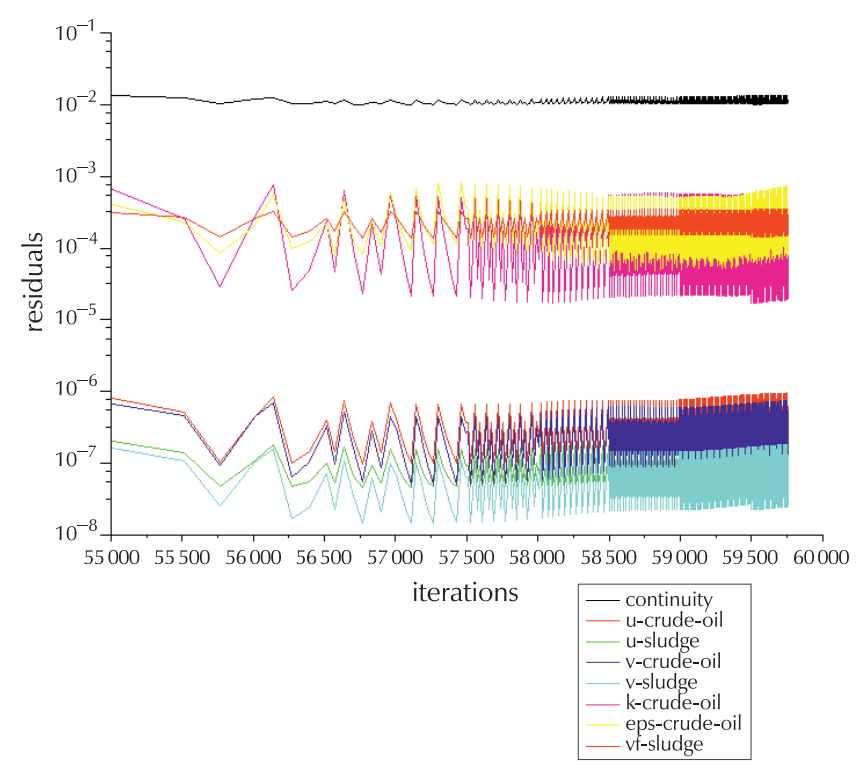

Fig. 12 - Residual diagram
Distribution of sludge: Sludge reduction system with the application of SRJ (Submerged Rotary Jet) has been used on two crude oil storage tanks T-4001, T4123 in a tank farm in Iran. In this system, the crude oil was sucked from the storage tank by a pump and re-injected at higher pressure into the centre of the tank bottom by means of a SRJ. This system was in service once a month for 24 hours, whereby 21 experiments were performed. In order to analyse the system results, sludge height was measured before each test and compared with a similar tank without an SRJ system. The results showed $90 \%$ efficiency of sludge reduction for 1000000 barrel tank (95\% sludge reduction in tank with SRJ in comparison with tank without SRJ.) (Fig. 13).

Fig. 13 illustrates the sludge accumulation rate as a function of time. According to this figure, the time interval between two tests lasted 11 days more than one month, and the results showed an increasing trend in sludge formation. In addition, according to the modelling results, the thickness of the sludge averagely reduced from $100 \mathrm{~cm}$ at the tank bottom to less than $20 \mathrm{~cm}$, indicating a reasonable correlation with the results obtained from the sludge profile of the tank bottom (Fig. 13).

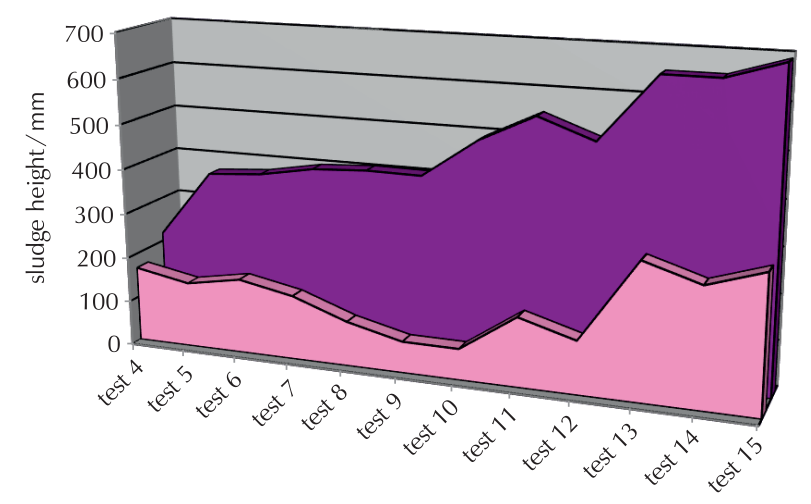

Fig. 13 - Sludge thickness profile with and without SRJ

\section{Conclusion}

In this paper, modelling of mixing fluid in a one-million-barrel tank has been analysed as sludge preventive method. Firstly, modelling of the mixing process was conducted, and different multiphase flows were studied. The proper technique for modelling (Euler) was then chosen among three methods. After providing and meshing this model, two-dimensional and two-phase modelling were performed by software fluent. According to initial results, the oil jet penetrated into the sludge of the tank bottom approximately in the first minute. Subsequently, the jet impacted the left wall and during this time the sludge mixed partially with the oil. As mixing time passed, the sludge and oil mixing pattern improved significantly, and the jet began to remove the sludge with higher velocity on the right side of the tank when the flow returned from the wall. Thus, it is reasonable to assume SRJ in the fixed situation because of performing the simulation in a short time. Based on the velocity model, the penetration rate of the fluid jet 
reduced over time, and the shearing force caused rotational and circulatory flow to extend along the entire 7 meters of tank height. Therefore, a circulatory flow with a length of $57 \mathrm{~m}$ and height of $7 \mathrm{~m}$ besides five internal circulation flows were produced in the model. This condition leads to proper mixing and complete sludge removal from the bottom of the tank in the first minute. Model verification using the software and experimental data indicated that less acceptable quantities of $y^{+}(<300)$ are related to the sludge on the wall and the bottom of the tank. The results of variation in jet output velocity confirm the effect of the jet velocity model and amount on the mixing process. In other words, by increasing velocity from $5 \mathrm{~m} \mathrm{~s}^{-1}$, the velocity model improved significantly, and had an effect on the mixing process. The velocity model shows no noticeable changes in the following steps, but as the velocity increased, the mixing process improved. From the velocity of $30 \mathrm{~m} \mathrm{~s}^{-1}$ and above, rotational and circular patterns, as the main factors of mixing, had formed, which obviously had an effect on the improvement of mixing quality.

\section{ACKNOWLEDGEMENTS}

The authors gratefully acknowledge the financial support of the R\&D Group, Iranian Oil Terminal Company (IOTC), and the University Jehad, Branch of Science \& Technology University (JDEVS).

\section{List of abbreviations and symbols}

SRJ

- submerged rotary jet

CFD - computational fluid dynamics

epsilon-crude-oil - disappearance rate of turbulent

K-crude-oil - kinetic energy of turbulent

U-crude-oil - crude oil velocity in $x$ direction

U-sludge - sludge velocity in $x$ direction

$\mathrm{V}$-crude-oil - crude oil velocity in y direction

V-sludge - sludge velocity in y direction

$\vec{F}_{\text {lift } q} \quad-$ lift force

$F_{q} \quad-$ external force

$\dot{m}_{p q} \quad$ - mass transport from phase $p$ to $q$

$\dot{m}_{q p} \quad-$ mass transport from phase $q$ to $p$

$S_{q} \quad-$ constant mass source

$V_{q} \quad-$ volume of each phase

$\begin{array}{ll}\vec{v} & - \text { phase velocity } \\ \alpha_{q} & - \text { volume of fluid } \\ \lambda_{q} & - \text { bulk of phase } q \\ \mu_{q} & - \text { shear viscosity } \\ \rho_{q} & - \text { density of each phase } \\ \overline{\bar{\tau}}_{q} & - \text { stress-strain tensor }\end{array}$

\section{References}

\section{Literatura}

1. M. Toru, N. Tomoyuki, M. Tsukasa, S. Hisashi, Removal of oil tank bottom sludge by novel biosurfactant, JE1058BS, J. Jap. Petro. Inst. 55 (2012) 138-141, doi: https://doi.org/10.1627/ jpi.55.138.

2. G. M. Heath, R. A. Heath, Z. Dundr, Paraffinic sludge reduction in crude oil storage tanks through the use of shearing and re suspension, Act. Monta. Slov. 9 (2004) 184-188, doi: https:// doi.org/10.1093/acprof:oso/9780199259205.001.0001.

3. K. L. Wasewar, A design of jet mixed tank, Chem. Biochem. Eng. Q. 20 (2006) 31-46.

4. E. L. Paul, V. A. Atiemo-Obeng, S. M. Kresta, Handbook of industrial mixing science and practice, John Wiley \& Sons, 2004, doi: https://doi.org/10.1002/0471451452.

5. H. Fosset, The action of free jets in mixing of fluids, Tran. of the Inst. of Chem. Eng. 29 (1951) 322-332.

6. E. A. Fox, V. E. Gex, Single-Phase blending of liquids, AIChE J. 2 (1956) 539-544, doi: https://doi.org/10.1002/ aic.690020422.

7. P. W. Coldrey, Jet mixing, I. Chem. E. Course, Univ. of Bradford, England, 1978.

8. A. C. G. Lane, P. Rice, An investigation of liquid jet mixing employing an inclined side entry jet, Tran. of the Inst. of Chem. Eng. 60 (1982) 171-176.

9. T. Mauyama, Y. Ban, T. Mizushina, Jet mixing of fluids in tanks, J. of Chem. Eng. of Jap. 15 (1982) 342-348, doi: https://doi. org/10.1252/jcej.15.342.

10. V. V. Ranade, Towards better mixing protocols by designing spatially periodic flows-The case of a jet mixer, Chem. Eng. Sci. 51 (1996) 2637-2642, doi: https://doi. org/10.1016/0009-2509(96)00129-7.

11. S. Jayanti, Hydrodynamics of jet mixing in vessels, Chem. Eng. Sci. 56 (2001) 193-210, doi: https://doi.org/10.1016/ S0009-2509(99)00588-6.

12. A. W. Patwardhan, CFD modeling of jet mixed tanks, Chem. Eng. Sci. 57 (2002) 1307-1318, doi: https://doi.org/10.1016/ S0009-2509(02)00049-0.

13. H. D. Zughbi, M. A. Rakib, Mixing in a fluid jet agitated tank: effects of jet angle and elevation and number of jets, Chem. Eng. Sci. 59 (2004) 829-842, doi: https://doi.org/10.1016/j. ces.2003.09.044. 


\title{
SAŽETAK
}

\section{Izučavanje CFD-om utjecaja brzine mlaza na miješanje i nastajanje mulja u velikim spremnicima sirove nafte}

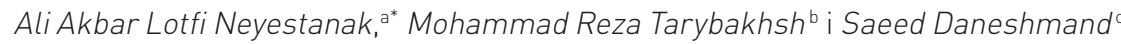

Računalnom dinamikom fluida modeliran je utjecaj brzine mlaza potopljene rotacijske mlazne miješalice na nastajanje mulja u velikim spremnicima nafte. U dvodimezionalnom CFD modelu primijenjena je Euler-Eulerova metoda za opisivanje toka nafte i mulja na dnu spremnika. Uz promjenu nekih parametara modelom k-e opisana je turbulencija toka miješanja. Rezultati pokazuju da na miješanje utječu brzina mlaza, kut i vrijeme miješanja. Povećanjem brzine od $5 \mathrm{~m} \mathrm{~s}^{-1}$ način miješanja znatno se mijenja i poboljšano je miješanje mulja sa sirovom naftom.

Rezultati su procijenjeni proučavanjem odabranog profila mulja na dnu spremnika uzorka, a modeliranje pokazuje smanjenje debljine sloja mulja za $80 \mathrm{~cm}$, što se slaže s profilom dna spremnika. Os $y^{+}$u svim točkama pokazuje iznose manje od 300, što je prihvatljivo u dvofaznom modeliranju.

\section{Ključne riječi}

Potopljena rotacijska mlazna miješalica, veliki naftni spremnik, sprječavanje stvaranja mulja, modeliranje protoka fluida, računalna dinamika fluida, Euler-Eulerova metoda

a Department of Engineering, Yadegar -e- Imam

Izvorni znanstveni rad Khomeini (RAH) Shahre Rey Branch, Islamic Azad University, Tehran, Iran

${ }^{\mathrm{b}}$ Department of Chemical Engineering, Iran Prihvaćeno 29. lipnja 2016.

University of Science \& Technology, Teheran,

Iran

' Department of Mechanical Engineering, Majlesi Branch, Islamic Azad University, Isfahan, Iran 